PROC. OF JSCE,

No. 242, OCT. 1975

\title{
MULTISPAN SUSPENSION BRIDGES UNDER TORSIONAL LOADING
}

\author{
By Takeo FUKUDA*
}

\section{INTRODUCTION}

The problem of torsion of suspension bridges has become to be much studied and discussed after the failure in 1940 of the first Tacoma Narrows Bridge. Studies made associated with the investigation on the causes of the accident, however, were mostly directed to the dynamic behavior such as torsional oscillation or flapping motion and, strange to say, relatively few works can be found on the statical analysis of suspension bridges for torsion. Sih ${ }^{1)}$ presented in 1957 a paper on the torsional analysis of truss-stiffened suspension bridges. This paper is devoted rather to the stress analysis of stiffening trusses and is very brief and cannot be said extensive. In 1960 and 1961, Baron and Arioto ${ }^{2), 3)}$ presented comprehensive papers on the torsional analysis and behavior of suspension bridge towers. Recently (in 1974), Irvine ${ }^{4}$ presented a paper on the torsional analysis of suspension bridges stiffened with box-girders as the Severn Bridge in Great Britain and the Bosporus Bridge in Turkey. The analysis was made by considering the main span of a three-span bridge as a single-span, and that loaded with a uniform torque or a point torque. Besides, the analysis was based on equations that include some approximations. But Irvine's analysis can be said rational and practical.

The Task Committee on Steel Superstructures of Bridges Between Honshu and Shikoku organized in the Japan Society of Civil Engineers on commission of the Honshu-Shikoku Bridge Authority presented in 1973 a special report titled "Torsional Analysis of Suspension Bridges," 5) compiling studies of some few researchers, one of which is the one recently presented as a separate paper $^{6}$. Computations are made by first assuming the value of horizontal cable tension, i.e., by the trial-and-error method, and the ap-

* Prof. Emeritus, Univ. of Tokyo. proximation method of Galerkin or Laplace transformation is used to solve differential equations. While the stiffening trusses were viewed as space trusses, relatively little attention was paid to the cables and towers.

In the following is presented a method of analysis of multispan suspension bridges for asymmetric vertical loads that cause torsion in the bridge structure. The main features and assumptions of the present paper are as follows:

1. The structure is so constructed that all dead loads are sustained by the cable and the horizontal cable tension due to dead loads becomes uniform throughout the bridge; and the state of equilibrium under dead loads is taken as the origin or the initial state of the analysis;

2. Suspenders are viewed as isolated members which they are, and the analysis is made by solving simultaneous equations instead of resorting to differential equations;

3. Vertical and horizontal cable movements as well as the changes in the cable slope are taken into account in considering the cable equilibrium after deformation, but the length changes of suspenders are disregarded;

4. The bridge structure is symmetric about its center line; stiffening trusses on either side of the bridge are assumed each as a girder with a constant moment of inertia in each span; against torsion, however, the suspended structure is assumed to behave as a closed-box girder, its equivalent St. Venant torsion constant being constant in each span; and

5. The method presented can be applied to bridges with any number of spans; the cables may be free to move in the direction of bridge axis or are anchored at tower tops; in the latter case, the flexural and torsional stiffnesses of towers are taken into consideration.

All live loads are considered to concentrate at points where suspenders are joined to stiffening trusses; these loads need not be uniform; they may vary point by point. Let $: P_{i}$ and $P_{i}^{\prime}=$ live 
loads acting at opposite lying points, $i$ and $i^{\prime}$, of the stiffening truss. Instead of considering $P_{i}$ and $P_{i}^{\prime}$ as they act, the analysis 'is carried out by substituting them by a set of symmetric loads, $P_{i}^{*}=\frac{1}{2}\left(P_{i}+P_{i}^{\prime}\right)$, and another set of antisymmetric loads, $\bar{P}_{i}=\frac{1}{2}\left(P_{i}-P_{i}{ }^{\prime}\right)$. Computations are made separately for the symmetric loading of $P_{i}^{*}$ and for the antisymmetric loading of $\bar{P}_{i}$ and then the results for $P_{i}{ }^{*}$ and $\bar{P}_{i}$ are added together to get the final results.

This is nothing but a method of superposition. It might be argued that the law of superposition cannot be applied to suspension bridges in which there holds no linear relationship between the deformation and the applied loads. Theoretically, this cannot be refuted. In a long-span suspension bridge, however, in which the dead load is far in excess of live loads, insofar as the analysis is made only for the live loads by taking the state of equilibrium under dead loads as the origin of the analysis, the linear relationship may well be assumed. Besides, the deformation and stress changes due to torsional loading usually do not amount to so much as the maximums that will arise from full-width live loads. It may be said, therefore, that enough approximate results will be obtained by the above-mentioned procedure.

\section{BASIC EQUATIONS}

\section{(1) Displacements and Stress Changes of Cable Segment}

Referring to the cable segment left of panel point $i$ shown in Fig. 1, let $\lambda_{i}=$ initial panel length; $l_{i}$ and $\Delta l_{i}=$ initial segmental length and its increment; $\phi_{i}$ and $\Delta \phi_{i}=$ initial angle of slope and its increment; $u_{i}=$ horizontal displacement of $i$ in the direction of bridge axis, positive to the right; and $v_{i}=$ vertical deflection of $i$.

If $N_{a, i}$ and $V_{a, i}=$ cable tension and its vertical component in the cable segment in the initial

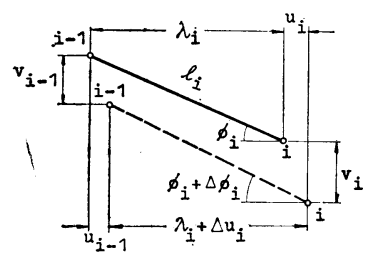

Fig. 1 Displacement of Fig. 2 Cable Tension Cable Segment.

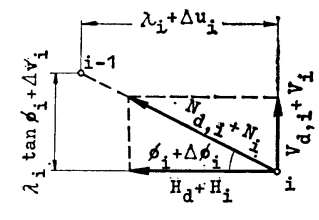

After Deformation. state, they are related to $H_{d}$ by

$$
N_{d, i}=H_{d} \sec \phi_{i}, \text { and } V_{d, i}=H_{d} \tan \phi_{i} \cdots .
$$

in which $H_{d}=$ horizontal component of cable tension (horizontal cable tension) due to deal loads, assumed constant throughout the bridge.

When live loads are applied, the cable tension will change. If the increments of $N_{d, i}, V_{d, i}$, and $H_{d}$ are denoted by $N_{i}, V_{i}$, and $H_{i}$, respectively (see Fig. 2), they can be expressed by the following equations which were derived in the writer's previous paper ${ }^{7)}$.

$$
\begin{aligned}
N_{i} & =E_{c} A_{c}\left(\Delta u_{i} \cos \phi_{i}+\Delta v_{i} \sin \phi_{i}\right) / l_{i} \\
H_{i} & =E_{c} A_{c}\left(\alpha_{i} \Delta u_{i}+\beta_{i} \Delta v_{i}\right) / l_{i} \ldots \ldots \ldots \ldots \ldots \ldots \ldots \ldots \ldots \ldots \\
V_{i} & =E_{c} A_{c}\left(\beta_{i} \Delta u_{i}+\gamma_{i} \Delta v_{i}\right) / l_{i} \ldots \ldots \ldots \ldots \ldots \ldots \ldots
\end{aligned}
$$

in which $E_{c}=$ modulus of elasticity of cable; $A_{c}=$ cable area;

$$
\Delta u_{i}=u_{i}-u_{-1} \text {, and } \Delta v_{i}=v_{i}-v_{i-1}
$$

and

$$
\begin{aligned}
& \alpha_{i}=\cos ^{2} \phi_{i}+\kappa \sin \phi_{i} \tan \phi_{i}, \\
& \beta_{i}=\sin \phi_{i}\left(\cos \phi_{i}-\kappa\right), \quad \text { and } \\
& \gamma_{i}=\sin ^{2} \phi_{i}+\kappa \cos \phi_{i} ;
\end{aligned}
$$

in which

$$
\kappa=\frac{H_{d}+H_{i}}{E_{c} A_{c}}
$$

The parameter, $\kappa$, is in no way constant; it varies with $H_{i}$. Therefore, the analysis becomes nonlinear. For a long-span bridge, however, in which the dead load is far greater than live loads, the effect of the variation in the value of $\kappa$ is negligibly small so that, disregarding $H_{i}$ as compared with $H_{d}, \kappa$ can be defined by

$$
\kappa=\frac{H_{d}}{E_{c} A_{c}}
$$

which is called the coefficient of horizontal cable tension. Thus, the analysis has become linear.

It is a common practice to support stiffening trusses by movable bearings and to install center ties between the cables and trusses at midspan. In this kind of construction, the stiffening trusses will move in the direction of bridge axis along with the cables and suspenders will remain neariy vertical. Accordingly, the horizontal components of suspender tension can be disregarded and the horizontal cable tension becomes uniform throughout the bridge, or throughout a span at least. Therefore, $H_{i}$ will hereafter be denoted by $H_{m n}$, the subscript, $m n$, denoting that a span between $m$ and $n$ is referred to.

Now, if $H_{m n}$ is taken as one of the basic unknowns, $\Delta u_{i}$ and $V_{i}$ become, from Eqs. 3 and 4 , as follows: 


$$
\begin{aligned}
& \Delta u_{i}=a_{i} \frac{H_{m n}}{E_{c} A_{c}} l_{i}-b_{i} \Delta v_{i} \\
& V_{i}=a_{i} \frac{\Delta v_{i}}{\lambda_{i}} H_{d}+b_{i} H_{m n}
\end{aligned}
$$

in which

$$
a_{i}=1 / \alpha_{i}, \text { and } b_{i}=\beta_{i} / \alpha_{i}
$$

\section{(2) Increment in Suspender Tension}

If the increment in suspender tension at $i$ is denoted by $T_{i}$, it equals $V_{i}-V_{i+1}$. Hence, from Eq. 9:

$$
T_{i}=\left[a_{i} \frac{\Delta v_{i}}{\lambda_{i}}-a_{i+1} \frac{\Delta v_{i+1}}{\lambda_{i+1}}\right] H_{d}+\left(b_{i}-b_{i+1}\right) H_{m n}
$$

\section{(3) Flexure of Stiffening Truss}

The analysis is made by dividing the stiffening truss into equal panels. Fig. 3 being referred to, let $E I_{m n}=$ flexural rigidity of the stiffening truss in span $m n ; L_{i}=$ vertical load to be sustained by the truss at $i ; y_{i}=$ vertical deflection of panel point $i$; and $\lambda_{m n}=$ equidistant panel length. Then, from structural mechanics:

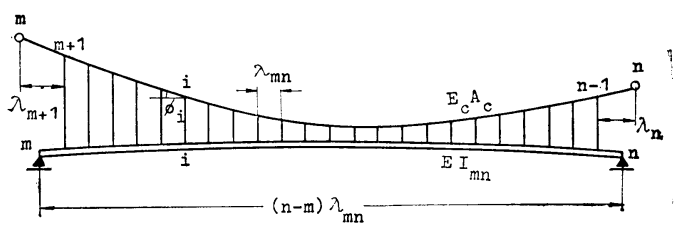

Fig. 3 Span between $m$ and $n$.

$$
\begin{aligned}
& M_{i-1}-2 M_{i}+M_{i+1}=-\lambda_{m n} L_{i} \\
& y_{i-1}-2 y_{i}+y_{i+1}=-\frac{\lambda_{m n}^{2}}{6 E I_{m n}}\left(M_{i-1}+4 M_{i}+M_{i+1}\right)
\end{aligned}
$$

which are to be applied to $i=m+1, \cdots, n-1$. But, in applying them to $i=m+1$ and $i=n-1$, it must be noted that $L_{i}, M_{i}$, and $y_{i}$ vanish for $i=m$ and $i=n$.

Now, a new quantity, $X_{i}$, which is proportional to $\Delta y_{i}=y_{i}-y_{i-1}$, is introduced as the basic unknown:

$$
X_{i}=\frac{1}{\rho_{m n}} \Delta y_{i}, \quad \text { or } \quad \Delta y_{i}=\rho_{m n} X_{i}(i=m+1, \cdots, n)
$$

in which

$$
\rho_{m n}=\frac{\lambda_{m n}^{3}}{6 E I_{m n}}
$$

$X_{i}$ has the dimension of force and $\rho_{m n}$ is a constant proper to span $m n$, having the dimension of length by force.
Eqs. 12 and 13 are difference equations of second order with respect to $M_{i}$ and $y_{i}$, respectively. If $M_{i}$ is eliminated from Eqs. 12 and 13 and $\Delta y_{i}$ is expressed in terms of $X_{i}$ by Eq. 14, noting thereby the boundary conditions at span ends, the following set of equations with respect to $X_{i}$ is obtained:

$$
\begin{gathered}
2 X_{m+1}-3 X_{m+2}+X_{m+3}=4 L_{m+1}+L_{m+2} ; \\
-X_{i-1}+3 X_{i}-3 X_{i+1}+X_{i+2}=L_{i-1}+4 L_{i} \\
+L_{i+1}, \quad(i=m+2, \cdots, n-2) ; \\
-X_{n-2}+3 X_{n-1}-2 X_{n}=L_{n-2}+4 L_{n-1}
\end{gathered}
$$

Next, there occurs no vertical displacement at both ends of the stiffening truss so that the total sum of $\Delta y_{i}$ from $i=m+1$ to $i=n$ must vanish. As $\Delta y_{i}$ is proportional to $X_{i}$, the sum of $X_{i}$ must also vanish, i.e.,

$$
\sum_{i=m+1}^{n} X_{i}=0
$$

Eqs. 16 and 17 are the basic equations derived from the condition of the flexure of the stiffening truss. They shall be applied to each span of the bridge.

All the foregoing equations, Eqs. 1 to 17, are those derived with respect to either one side of the bridge. They hold also on the opposite side. To distinguish the quantities that vary according to the bridge side, those on the opposite side are marked with a prime, as $u_{i}{ }^{\prime}, v_{i}{ }^{\prime}, H_{m n}{ }^{\prime}, X_{i}{ }^{\prime}$, etc. But, the structural data such as $A_{c}, I_{m n}, H_{d}$, $\rho_{m n}$, etc., and the parameters, $a_{i}$ and $b_{i}$, remain the same for both sides.

\section{ANALYSIS FOR SYMMETRIC LOADING}

As noted in Introduction, the actual loading, $P_{i}$ on one side and $P_{i}^{\prime}$ on the opposite side of the bridge, is substituted by the symmetric loading of $P_{i}^{*}=\left(P_{i}+P_{i}{ }^{\prime}\right) / 2$ and the antisymmetric loading of $\vec{P}_{i}=\left(P_{i}-P_{i}{ }^{\prime}\right) / 2$. In the case of the symmetric loading, the deformation and stress changes become equal on both sides and they are indicated with an asterisk, as $u_{i}^{*}, y_{i}^{*}, H_{m n}^{*}$, $X_{i}{ }^{*}$, etc. To determine these values, it suffices to make the analysis on either one side.

In the case of the symmetric loading, there occurs no twist and the cables and stiffening trusses undergo the same vertical deflection, i.e., $v_{i}^{*}=y_{i}{ }^{*}$. Hence, from Eq. 14,

$$
\Delta v_{i}^{*}=\Delta y_{i}{ }^{*}=\rho_{m n} X_{i}^{*}, \quad(i=m+1, \cdots, n)
$$

substitution of which into Eq. 11 renders 


$$
\begin{array}{r}
T_{i}^{*}=k_{i} X_{i}^{*}-k_{i+1} X_{i+1}^{*}+\left(b_{i}-b_{i+1}\right) H_{m n}^{*}, \\
(i=m+1, \cdots, n-1) \ldots \ldots \ldots \ldots
\end{array}
$$

in which $k_{i}$ is a dimensionless parameter defined by

$$
k_{i}=\rho_{m n} H_{d}\left(a_{i} / \lambda_{i}\right), \quad(i=m+1, \cdots, n)
$$

in which $\lambda_{i}$ shall be taken $\lambda_{m+1}$ and $\lambda_{n}$ for $i=$ $m+1$ and $i=n$, respectively, and $\lambda_{m n}$ for $\left.i=m+2,\right]$ $\cdots, n-1$.

$T_{i}{ }^{*}$ acts upwards on the stiffening truss. Therefore, the load to act on the stiffening truss at $i$, $L_{i} *$, becomes:

$$
\begin{aligned}
& L_{i} *=P_{i}^{*}-T_{i} * \\
& =P_{i}^{*}-k_{i} X_{i}^{*}+k_{i+1} X_{i+1}^{*}-\left(b_{i}-b_{i+1}\right) H_{m n}^{*}, \\
& (i=m+1, \cdots, n-1)
\end{aligned}
$$

Now, if Eq. 21 is substituted for $L_{i}$ in Eq. 16, the following set of basic equations for $X_{i}^{*}$ and $H_{m n}^{*}$ is obtained.

$$
\begin{aligned}
& A_{m+1} X_{m+1}^{*}-A_{m+2} X_{m+2}^{*}+B_{m+3} X_{m+3}^{*}+C_{m+1} H_{m n}^{*} \\
& \quad=4 P_{m+1}^{*}+P_{m+2}^{*} ; \\
& -B_{i-1} X_{i-1}^{*}+A_{i} X_{i}^{*}-A_{i+1} X_{i+1}^{*}+B_{i+2} X_{i+2}^{*}+C_{i} H_{m n}^{*} \\
& \quad=P_{i-1}^{*}+4 P_{i}^{*}+P_{i+1}^{*} ; \quad(i=m+2, \cdots, n-2) \\
& -B_{n-2} X_{n-2}^{*}+A_{n-1} X_{n-1}^{*}-A_{n} X_{n}^{*}+C_{n-1} H_{m n}^{*} \\
& \quad=P_{n-2}^{*}+4 P_{n-1}^{*}
\end{aligned}
$$

in which

$$
\begin{aligned}
& A_{m+1}=2+4 k_{m+1}, \quad A_{n}=2+4 k_{n}, \\
& A_{i}=3\left(1+k_{i}\right), \quad(i=m+2, \cdots, n-1) ; \\
& B_{i}=1-k_{i}, \quad(i=m+1, \cdots, n) ; \\
& C_{m+1}=4 b_{m+1}-3 b_{m+2}-b_{m+3}, \\
& C_{i}=b_{i-1}+3 b_{i}-3 b_{i-1}-b_{i-2}, \\
& \quad(i=m+2, \cdots, n-2) ; \\
& C_{n-1}=b_{n-2}+3 b_{n-1}-4 b_{n}
\end{aligned}
$$

$$
\sum_{i=m+1}^{n} X_{i}^{*}=0
$$

Eqs. 22 and 24 are applied to each span and as many equations as $X_{i}^{*}$ will be obtained. But, these equations include yet unknown $H_{m n}^{*}$. Therefore, as many more equations as the unknown $H_{m n}^{*}$ are needed. These equations are derived from the condition of cable movement at span ends.

If $\Delta v_{i} *$ of Eq. 18 is substituted for $\Delta v_{i}$ in Eq. 8 , the result is:

$$
\begin{array}{r}
\Delta u_{i} *=\frac{1}{E_{c} A_{c}} a_{i} l_{i} H_{m n}^{*}-\rho_{m n} b_{i} X_{i}^{*}, \\
(i=m+1, \cdots, n) \cdots \cdots \cdots \cdots
\end{array}
$$

The sum of $\Delta u_{i}^{*}$ from $i=m+1$ to $i=n$ equals $u_{n}^{*}-u_{m}^{*}$. Therefore,

$$
L_{m n}-H_{m n}^{*}-D_{m n} \sum_{i=m+1}^{n} b_{i} X_{i}^{*}=E_{c} A_{c}\left(u_{n}^{*}-u_{m}^{*}\right)
$$

in which

$$
L_{m n}=\sum_{i=m+1}^{n} a_{i} l_{i}, \text { and } D_{m n}=E_{c} A_{c} \rho_{m n}
$$

Both $L_{m n}$ and $D_{m n}$ are constants characteristic of the span concerned, having the dimension of length. $L_{m n}$ depends on the cable configuration and $D_{m n}$ on the structural properties of the stiffening truss.

Eq. 26 corresponds to what is commonly called the cable equation. It includes the cable displacements at span ends, $u_{m}^{*}$ and $u_{n}^{*}$, that depend on the condition of cable support, as described below.

\section{(1) When Cable is Anchored at Tower Tops}

When the cable is anchored at tower top $m$, the cable movement, $u_{m}^{*}$, equals the tower-top movement that can be assumed proportional to the unbalance of the horizontal cable tension across the tower top. Let the span lying to the left of tower top $m$ be $j m$ as shown in Fig. 4, $u_{m}^{*}$ can be expressed as

$$
u_{m}^{*}=\left(H_{m n}^{*}-H_{j m}^{*}\right) / \mu_{m}^{*} \text {, or } u_{m}^{*}=\eta_{m}^{*}\left(H_{m n}^{*}-H_{j m}^{*}\right)
$$

in which $\mu_{m}^{*}=$ the flexural spring constant of tower top $m$, and $\eta_{m}^{*}=$ the reciprocal of $\mu_{m}^{*}$. As there occurs no torsion in the case of the symmetrical loading, these constants can be obtained by analyzing either tower leg as a beam-column.

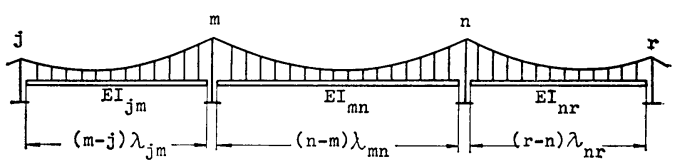

Fig. 4 Three Consecutive Spans.

An equation similar to Eq. 28 will be obtained for $u_{n}^{*}$. Substitution of these equations for $u_{m}^{*}$ and $u_{n}^{*}$ in Eq. 26 yields

$$
\begin{array}{r}
D_{m n} \sum_{i=m+1}^{n} b_{i} X_{i}^{*}+d_{m}^{*} H_{j m}^{*}-\left(L_{m n}+d_{m}^{*}+d_{n}^{*}\right) H_{m n}^{*} \\
+d_{n}^{*} H_{n r}^{*}=0 \ldots \ldots \ldots \ldots \ldots \ldots \ldots \ldots \ldots \ldots \ldots \ldots \ldots
\end{array}
$$

in which

$$
d_{m}^{*}=E_{c} A_{c} \eta_{m}^{*} \text {, and } d_{n}^{*}=E_{c} A_{o} \eta_{n}^{*}
$$

the dimension of which is length.

Eq. 29 is applied to each span and as many 
equations as the unknown $H_{m n}^{*}$ will be obtained. Thus, the total number of equations of Eqs. 22, 24 , and 29 equals the total number of the unknowns, $X_{i}^{*}$ and $H_{m n}^{*}$, and simultaneous solution of these equations will render the unknowns.

\section{(2) When Cable is Movable at Tower Tops}

For example, let the three spans shown in Fig. 4 be viewed as a three-span bridge in which the cable rests on movable saddles at tower tops $m$ and $n$. In this case, the horizontal cable tension is always uniform throughout the bridge and its increment is denoted simply by $H^{*}$. Assuming both anchorages immovable, the summation of $\Delta u_{i}{ }^{*}$ is extended from $i=j+1$ to $i=r$, and the following cable equation is obtained.

$$
\begin{array}{r}
D_{j m} \sum_{j+1}^{m} b_{i} X_{i} *+D_{m n} \sum_{m+1}^{n} b_{i} X_{i} *+D_{n r} \sum_{n+1}^{r} b_{i} X_{i}^{*} \\
-\left(L_{j m}+L_{m n}+L_{n r}\right) H^{*}=0
\end{array}
$$

in which $D_{j m}, D_{n r}, L_{j m}$, and $L_{n r}$ are the constants to be obtained by applying Eq. 27 to spans $j m$ and $n r$, respectively.

Eq. 31 is what is to be solved simultaneously with Eqs. 22 and 24 . It might be thought that if $H^{*}$ is solved from Eq. 31 and substituted into Eq. 22, $H^{*}$ will be eliminated and equations with respect only to $X_{i}^{*}$ will be obtained. But, this results in very complicated equations and it is rather practical to solve Eq. 31 simultaneously together with Eqs. 22 and 24.

\section{(3) Displacements and Member Stresses}

Once $X_{i}^{*}$ and $H_{m n}^{*}$ are solved, the displacements and changes in member stresses can be computed in the following way.

a) Vertical Deflection of Cable and Stiffening Truss

The cable and stiffening truss undergo equal vertical deflection:

$$
v_{i}^{*}=y_{i}^{*}=\rho_{m n} \sum_{r=m+1}^{i} X_{r}^{*}, \quad(i=m+1, \cdots, n-1)
$$

b) Horizontal Displacement of Cable From Eq. 25:

$$
\begin{aligned}
u_{i}^{*}= & u_{m}^{*}+\frac{H_{m n}^{*}}{E_{c} A_{c}} \sum_{r=m+1}^{i} a_{r} l_{r}-\rho_{m n} \sum_{r=m+1}^{i} b_{r} X_{r} *, \\
& (i=m+1, \cdots, n) \cdots \cdots \cdots \ldots \ldots \ldots \ldots \ldots \ldots \ldots \ldots \ldots \ldots \ldots \ldots \ldots \ldots
\end{aligned}
$$

When the cable is anchored at tower top $m, u_{m}^{*}$ is computed by Eq. 28; when the cable is movable at tower tops, $u_{i}{ }^{*}$ must be computed by applying Eq. 33 successively from the left anchorage.

c) Increment is Suspender Tension
For $T_{i}^{*}$ holds Eq. 19.

d) Shear and Bending Moment of Stiffening Truss

The shear, $S_{i}{ }^{*}$, in the panel left of $i$ of the stiffening truss is

$$
\begin{aligned}
S_{i}^{*}= & \frac{1}{n-m}\left[-\sum_{r=m+1}^{i-1}(n-r)\left(P_{r}^{*}-T_{r}^{*}\right)\right. \\
& \left.+\sum_{r=i}^{n-1}(r-m)\left(P_{r}^{*}-T_{r}^{*}\right)\right], \quad(i=m+1, \cdots, n)
\end{aligned}
$$

Once $S_{i}{ }^{*}$ is known, the bending moment at $i$, $M_{i}^{*}$, can be computed by

$$
M_{i}^{*}=\lambda_{m n} \sum_{r=m+1}^{i} S_{r}^{*}, \quad(i=m+1, \cdots, n-1) \cdots
$$

Another equation for $M_{i}^{*}$ can be derived from Eqs. 12 and 13 when Eqs. 18, 19, and 21 are noted. The result is:

$$
\begin{aligned}
M_{i}^{*}=\frac{\lambda_{m n}}{6}\left[P_{i}^{*}-\right. & \left(b_{i}-b_{i+1}\right) H_{m n}^{*} \\
+ & \left.B_{i} X_{i}^{*}-B_{i+1} X_{i+1}^{*}\right], \\
& (i=m+1, \cdots, n-1)
\end{aligned}
$$

e) Change in Cable Tension

The change in the horizontal cable tension is $H_{m n}^{*}$ itself. If $\Delta v_{i}^{*}$ of Eq. 18 and $\Delta u_{i}^{*}$ of Eq. 25 are substituted for $\Delta v_{i}$ and $\Delta u_{i}$ in Eq. 2, respectively, the following equation for $N_{i}$ is obtained:

$$
\begin{aligned}
N_{i}= & a_{i} \cos \phi_{i} H_{m n}^{*}+k_{i} \sin \phi_{i} X_{i}^{*}, \\
& (i=m+1, \cdots, n) \cdots \cdots \cdots \cdots \cdots
\end{aligned}
$$

\section{ANALYSIS FOR ANTISYMMETRIC LOADING}

In the case of the antisymmetric loading of $\bar{P}_{i}=\left(P_{i}-P_{i}^{\prime}\right) / 2$, the structural deformation and stress changes become also antisymmetric about the bridge center line. In the following, the structural quantities that depends on $\bar{P}_{i}$ are denoted with a bar, as $\bar{v}_{i}, \bar{y}_{i}, \bar{H}_{m n}$, and $\bar{X}_{i}$, et al.

It is assumed that the cables are spaced in a width, $b_{c}$, that differs from the spacing of the stiffening trusses, $b$. Accordingly, the cables and stiffening trusses undergo unequal vertical displacement, $\bar{v}_{i}$ and $\bar{y}_{i}$, respectively. They are geometrically related by

$$
\bar{v}_{i}: \bar{y}_{i}=b_{c}: b
$$

Following Eq. 14, let the basic unknown be

$$
\begin{aligned}
& \bar{X}_{i}=\frac{1}{\rho_{m n}} \Delta \bar{y}_{i}, \quad \text { or } \quad \Delta \bar{y}_{i}=\rho_{m n} \bar{X}_{i} \\
&(i=m+1, \cdots, n) .
\end{aligned}
$$

then, if Eq. 37 is noted,

$$
\Delta \bar{v}_{i}=\left(b_{c} / b\right) \rho_{m n} \bar{X}_{i} \quad(i=m+1, \cdots, n) \cdots
$$


Substitution of Eq. 39 for $\Delta v_{t}$ in Eq. 11 renders

$$
\begin{array}{r}
\bar{T}_{i}=\left(b_{c} / b\right)\left(k_{i} \bar{X}_{i}-k_{i+1} \bar{X}_{i+1}\right)+\left(b_{i}-b_{i+1}\right) \bar{H}_{m n} \\
(i=m+1, \cdots, n-1) \cdots \ldots \ldots \ldots
\end{array}
$$

The antisymmetric loading causes twisting of the bridge structure. As the loads act concentrating at stiffening-truss panel points, the twisting moment to act on the suspended structure becomes uniform in each panel. Let $Z_{i}=$ twisting moment in the panel left of $i$, taken positive when it acts counterclockwise on the right-hand side of a section, it can be computed by, as derived in Appendix,

$$
\begin{aligned}
& Z_{i}=\nu_{m n} \bar{X}_{i} b \quad(i=m+1, \cdots, n), \\
& \text { in which } \nu_{m n}=\frac{G K_{m n}}{3 E I_{m n}}\left(\frac{\lambda_{m n}}{b}\right)^{2} \cdots
\end{aligned}
$$

in which $G=$ modulus of rigidity; and $K_{m n}=$ equivalent St. Venant torsion constant of the structure. $\nu_{m n}$ is a nondimensional constant that expresses the relative stiffness of the suspended structure against torsion and bending.

The unbalance of the twisting moment across section $i, Z_{i+1}-Z_{i}$, must be balanced by a couple of reactive forces exerted by the stiffening trusses. When these forces are taken into account, the panel point load, $\bar{L}_{i}$, the stiffening trusses on either side must sustain becomes as derived in Appendix:

$$
\begin{array}{r}
\bar{L}_{i}=\bar{P}_{i}-\bar{k}_{i} \bar{X}_{i}+\bar{k}_{i+1} \bar{X}_{i+1}-\left(\bar{b}_{i}-\bar{b}_{i+1}\right) \bar{H}_{m n} \\
(i=m+1, \cdots, n-1) \cdots \cdots
\end{array}
$$

in which

$$
\left.\begin{array}{ll}
\bar{k}_{i}=\left(b_{c} / b\right)^{2} k_{i}+\nu_{m n} & (i=m+1, \cdots, n) \\
\bar{b}_{i}=\left(b_{c} / b\right) b_{i} & (i=m+1, \cdots, n)
\end{array}\right\}
$$

If now Eq. 42 is substituted for $L_{i}$ in Eq. 15, the following set of basic equations is obtained:

$$
\begin{aligned}
& \bar{A}_{m+1} \bar{X}_{m+1}-\bar{A}_{m+2} \bar{X}_{m+2}+\bar{B}_{m+3} \bar{X}_{m+3} \\
& \quad+\bar{C}_{m+1} \bar{H}_{m n}=4 \bar{P}_{m+1}+\bar{P}_{m+2} ; \\
& -\bar{B}_{i-1} \bar{X}_{i-1}+\bar{A}_{i} \bar{X}_{i}-\bar{A}_{i+1} \bar{X}_{i+1}+\bar{B}_{i+2} \bar{X}_{i+2} \\
& \quad+\bar{C}_{i} \bar{H}_{m n}=\bar{P}_{i-1}+4 \bar{P}_{i}+\bar{P}_{i+1} ; \\
& \quad(i=m+2, \cdots n-2) \\
& -\bar{B}_{n-2} \bar{X}_{n-2}+\bar{A}_{n-1} \bar{X}_{n-1}-\bar{A}_{n} \bar{X}_{n}+\bar{C}_{n-1} \bar{H}_{m n} \\
& =\bar{P}_{n-2}+4 \bar{P}_{n-1}
\end{aligned}
$$

in which

$$
\left.\begin{array}{lc}
\bar{A}_{m+1}=2+4 \bar{k}_{m+1} ; & \bar{A}_{n}=2+4 \bar{k}_{n} ; \\
\bar{A}_{i}=3\left(1+\bar{k}_{i}\right), & (i=m+2, \cdots, n-1) ; \\
\bar{B}_{i}=1-\bar{k}_{i}, & (i=m+1, \cdots, n) ; \\
\bar{C}_{i}=\left(b_{c} / b\right) C_{i}, & (i=m+1, \cdots, n-1)
\end{array}\right\}
$$

Eq. 44 corresponds to Eq. 22 in the case of the symmetric loading. Another basic equation similar to Eq. 24 is derived from Eq. 17. Namely,

$$
\sum_{i=m+1}^{n} \bar{X}_{i}=0
$$

The cable equation in the case of the antisymmetric loading is, in general,

$$
L_{m n} \bar{H}_{m n}-D_{m n} \sum_{i=m+1}^{n} \bar{b}_{i} \bar{X}_{i}=E_{c} A_{c}\left(\bar{u}_{n}-\bar{u}_{m}\right)
$$

$L_{m n}$ and $D_{m n}$ in which are the same as used in Eq. 26. $\bar{u}_{m}$ and $\bar{u}_{n}$ are determined according to. the condition of cable support as described below.

\section{(1) When Cable is Anchored at Tower Tops}

The tower top movement due to $\bar{P}_{i}$ becomes antisymmetric in any case. The antisymmetric horizontal movement of tower top $m, \bar{u}_{m}$, can be: expressed by

$$
\bar{u}_{m}=\left(\bar{H}_{m n}-\bar{H}_{j m}\right) / \bar{\mu}_{m}, \quad \text { or } \quad \bar{u}_{m}=\bar{\eta}_{m}\left(\bar{H}_{m n}-\bar{H}_{j m}\right)
$$

in which $\bar{H}_{j m}$ and $\bar{H}_{m n}=$ increments in the horizontal cable tension in spans $j m$ and $m n$, respectively; $\bar{\mu}_{m}=$ torsional spring constant of tower top. $m$; and $\bar{\eta}_{m}=$ reciprocal of $\bar{\mu}_{m}$. These constants. must be evaluated by the torsional analysis of the tower, for which Baron and Arioto's paper ${ }^{2}$. will be of help.

An equation similar to Eq. 48 will be obtained for $\bar{u}_{n}$. Substitution of these equations in Eq. $47^{\prime}$ renders the following cable equation:

$$
\begin{array}{r}
D_{m n} \sum_{i=m+1}^{n} \bar{b}_{i} \bar{X}_{i}+\bar{d}_{m} \bar{H}_{j m}-\left(L_{m n}+\bar{d}_{m}+\bar{d}_{n}\right) \bar{H}_{m n} \\
\quad+\bar{d}_{n} \bar{H}_{n r}=0 \ldots \ldots \ldots \ldots \ldots \ldots \ldots \ldots \ldots \ldots \ldots \ldots \ldots \ldots \ldots \ldots \ldots \ldots \ldots \ldots \ldots \ldots \ldots \ldots \ldots \ldots \ldots
\end{array}
$$

in which

$$
\bar{d}_{m}=E_{c} A_{c} \bar{\eta}_{m}, \quad \text { and } \quad \bar{d}_{n}=E_{c} A_{c} \bar{\eta}_{n}
$$

\section{(2) When Cable is Movable at Tower Tops}

In this case, $\vec{H}_{m n}$ becomes uniform for all spans. and is denoted simply by $\bar{H}$. For the three-span. bridge shown in Fig. 4, the cable equation becomes identical with Eq. 31 except that $b_{i}, X_{i}^{*}$, and $H^{*}$ shall be changed to $\bar{b}_{i}, \bar{X}_{i}$, and $\bar{H}$, respectively.

\section{(3) Displacements and Member Stresses}

The horizontal cable displacement, $\bar{u}_{i}$, as well as the deflction, $\bar{y}_{i}$, bending moment, $\bar{M}_{i}$, and shear, $\bar{S}_{i}$, of stiffening trusses can be computed. by the equations for the case of $P_{i}^{*}$ by changing. $X_{i}^{*}, b_{i}, H_{m n}^{*}$, and $\eta_{m}^{*}$ to $\bar{X}_{i}, \bar{b}_{i}, \bar{H}_{m n}$, and $\bar{\eta}_{m}$, respectively.

The vertical cable displacement, $\bar{v}_{i}$, the increment in suspender tension, $\bar{T}_{i}$, and twisting moment, $Z_{i}$, shall be computed by Eqs. 37, 40, and 
41 , respectively. The angle of twist of the suspended structure, $\phi_{i}$, is

$$
\phi_{i}=2 \frac{\bar{y}_{i}}{b}, \quad(i=m+1, \cdots, n-1)
$$

and the increment in the cable tension, $\bar{N}_{i}$, is

$$
\bar{N}_{i}=a_{i} \cos \phi_{i} \bar{H}_{m n}+\left(b_{c} / b\right) k_{i} \sin \phi_{i} \bar{X}_{i},
$$

$$
(i=m+1, \cdots, n) \text {...... }
$$

\section{(4) Final Results}

Take, for example, the vertical deflction of stiffening trusses. Once the values of $y_{i}^{*}$ and $\bar{y}_{i}$ are known, the actual deflections on each side are computed by

$$
y_{i}=y_{i}^{*}+\bar{y}_{i}, \text { and } y_{i}^{\prime}=y_{i}^{*}-\bar{y}_{i}
$$

respectively. This procedure shall be applied also to other items except the twisting moment and angle of twist of the suspended structure that are unrelated to $P_{i}^{*}$ and are to be computed by Eqs. 41 and 51 , respectively.

\section{STRAIGHT BACKSTAY}

In some cases, cables in end spans are not attached to roadway structures and become to play the role of backstay. As these cables are practically straight, the backstay spans can be considered each as a single panel.

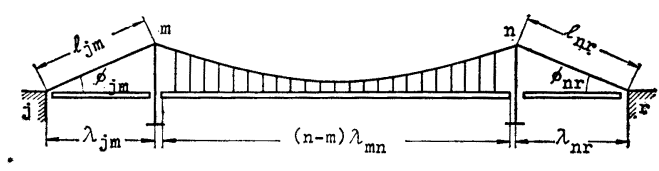

Fig. 5 Bridge with Backstay Spans.

Take Fig. 5, for example. Both side spans are viewed as single panels with cable length of $l_{j m}$ and $l_{n r}$, respectively. The parameters, $a_{i}$ and $b_{i}$, to be computed by Eq. 10 as well as the increment of the horizontal cable tension in the panel $j-m$ are denoted as $a_{j m}, b_{j m}$, and $H_{j m}$, respectively. Then, if Eq. 8 is applied to the panel $j \cdot m$ and it is noted that $u_{j}, v_{j}$, and $v_{m}$ must vanish, the following equation for $u_{m}$ is obtained.

$$
u_{m}=\frac{1}{E_{c} A_{c}} L_{j m} H_{j m}, \text { in which } L_{j m}=a_{j m} l_{j m}
$$

Eq. 54 holds also between $u_{m}^{\prime}$ and $H_{j m}^{\prime}$. Therefore, for $u_{m}^{*}$ and $\bar{u}_{m}$ :

$$
u_{m}^{*}=\frac{1}{E_{c} A_{c}} L_{j m} H_{j m}^{*}, \quad \text { and } \quad \bar{u}_{m}=\frac{1}{E_{c} A_{c}} L_{j m} \bar{H}_{j m}
$$

Similar equations will be obtained for $u_{n}^{*}$ and $\bar{u}_{n}$. These equations are what are to be substituted in the cable equations, Eqs. 26 and 47. However, further details are not given to comply with space limitation.

\section{EXAMPLE I-FOUR-SPAN BRIDGE}

To illustrate the proposed method and to know the torsional behavior of multispan suspension bridges, computations were made on a tentative design of a four-span highway bridge, shown in Fig. 6, planned for the crossing of the Kurushima Straits in Japan.

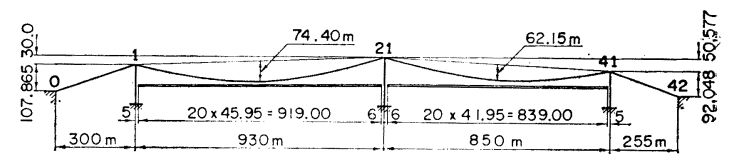

Fig. 6 Example of Four-Span Bridge.

\section{(1) Structural Properties}

The general dimensions of the bridge are shown in Fig. 6. The cables are assumed as fixed to tower tops by the friction between the cables and saddles. The cables and stiffening trusses are spaced in a same width of $27 \mathrm{~m}$. The cables in the end spans are not attached to roadway structures and so both end spans were assumed each as a single panel. Although it was well possible to make the analysis based on the actual suspender spacing, it was done by dividing each truss span into twenty equal panels. So, the division points were labeled as shown in Fig. 6, the left anchorage being labeled 0 , the tower tops 1,21 , and 41 , and the right anchorage 42 , respectively.

The cable area is: $A_{c}=0.4588 \mathrm{~m}^{2}$. The moment of inertia of the stiffening trusses in both main spans was estimated at $2.8 \mathrm{~m}^{4}$. As regards the St. Venant torsion constant of the suspended structure, $K$, it was estimated at $4.0 \mathrm{~m}^{4}$ from an approximate analysis on an equivalent thin-walled box section. Elastic constants were taken as: $E_{c}=196 \times 10^{6} \mathrm{kN} / \mathrm{m}^{2} ; E=206 \times 10^{6} \mathrm{kN} / \mathrm{m}^{2}$; and $G=$ $80 \times 10^{6} \mathrm{kN} / \mathrm{m}^{2}$.

The main tower was designed very stiff with a spring constant of $\mu_{21}^{*}=7845 \mathrm{kN} / \mathrm{m}$ for sym. metric loading. Its torsional spring constant was evaluated at $\bar{\mu}_{21}=37270 \mathrm{kN} / \mathrm{m}$. The side towers are stayed by the end-span cables and their stiffness scarcely affects the structural behavior of the bridge so that their spring constant was assumed as $1000 \mathrm{kN} / \mathrm{m}$ for symmetric and antisymmetric loading alike. 


\section{(2) Loading}

The dead load to be borne by the cable on either side was estimated at $141.1 \mathrm{kN} / \mathrm{m}$. This causes $H_{d}=205100 \mathrm{kN}$. The coefficient of horizontal cable tension becomes: $\kappa=0.002279$.

The bridge carries two separate 9 -m-wide roadways. The live loading specified by the HonshuShikoku Bridge Authority was adopted. The analysis was made for the antisymmetric loading shown in Fig. 7 (a), in which the linear loading is applied at each span center. The loads are applied as shown in Fig. 7 (b) and (c) and are transmitted to the stiffening trusses on either side as shown in Fig. 7 (d), from which the panel point loads, $P_{i}$ and $P_{i}^{\prime}$, and then the symmetric and antisymmetric loads, $P_{i}^{*}$ and $\bar{P}_{i}$, were evaluated.

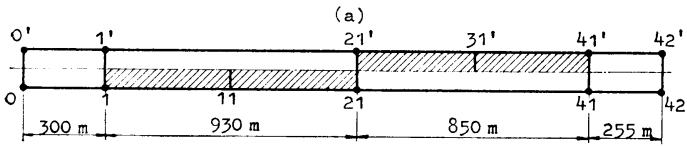

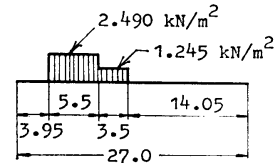

(b) Uniform Loading

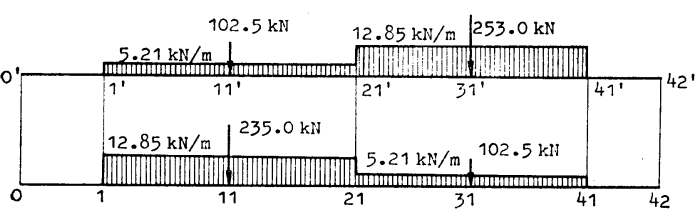

(d) Load Distribution on Each Side of Bridge

Fig. 7 Live Lording of Example I.

\section{(3) Results of Analysis}

The analysis was made by taking account of the structural feature that the tower tops are located at different elevations and the points of support of the stiffening trusses lie $6 \mathrm{~m}$ and $5 \mathrm{~m}$ distant from the main and side tower centers, respectively.

As already noted, the equivalent St. Venant torsion constant of the suspended structure, $K$, was estimated at $4.0 \mathrm{~m}^{4}$. However, in order to know the effect of the torsional stiffness of the suspended structure, comparative computations were made by disregarding the torsional stiffness, i.e., by assuming $K=0$, as well as by assuming $K=2.0$ and $6.0 \mathrm{~m}^{4}$.

First, the increments in the horizontal cable tension in each span and on each side as well as the unbalances across the main tower top are
Table 1 Increments in Horizontal Cable Tension, in Kilonewtons.

\begin{tabular}{l|r|r|r|r}
\hline Item & \multicolumn{1}{|c|}{$K=0$} & $K=2 m^{4}$ & $K=4 m^{4}$ & $K=6 m^{4}$ \\
\hline$H_{0,1}$ & 17029 & 14611 & 13985 & 13643 \\
$H_{1,21}$ & 16099 & 14673 & 14044 & 13701 \\
$H_{21,41}$ & 8685 & 10322 & 10956 & 11289 \\
$H_{41,42}$ & 8653 & 10286 & 10916 & 11289 \\
\hline$H_{0,1}^{\prime}$ & 8230 & 9683 & 10309 & 10650 \\
$H_{1,21}^{\prime}$ & 8265 & 9724 & 10353 & 10696 \\
$H_{21,41}^{\prime}$ & 15604 & 13967 & 13334 & 12963 \\
$H_{41,42}^{\prime}$ & 15549 & 13918 & 13289 & 12915 \\
\hline$\Delta H_{21}$ & -7414 & -4349 & -3088 & -2374 \\
$\Delta H_{21}^{\prime}$ & 7339 & 4242 & 2981 & 2267 \\
\hline
\end{tabular}

listed in Table 1 in kilonewtons. These increments are all about $7 \%$ or less of $H_{d}=205100 \mathrm{kN}$.

In the present example, the cables were assumed as fixed to tower tops by the friction between the cable and its saddle, and it was a matter of concern that the unbalance of the horizontal cable tension across the main tower top might become to exceed the safe limit of the friction, which, if the coefficient of the friction is taken 0.15 , lies in most cases at about onetenth of $H_{d}$, i.e., some $20000 \mathrm{kN}$ in the present case. The actual unbalance in the case of $K=$ $4.0 \mathrm{~m}^{4}$, however, was found to amount to mere $3000 \mathrm{kN}$ or so as given in Table 1 and so it was concluded that the antisymmetric loading presents no problem whatsoever regarding the cable anchorage at the main tower top. Across the side towers, there occurs scarcely any unbalance in the horizontal cable tension as can be seen in Table 1.

Of the various results of the analysis, the horizontal displacements of the cables, vertical deflections and bending moments of the stiffening

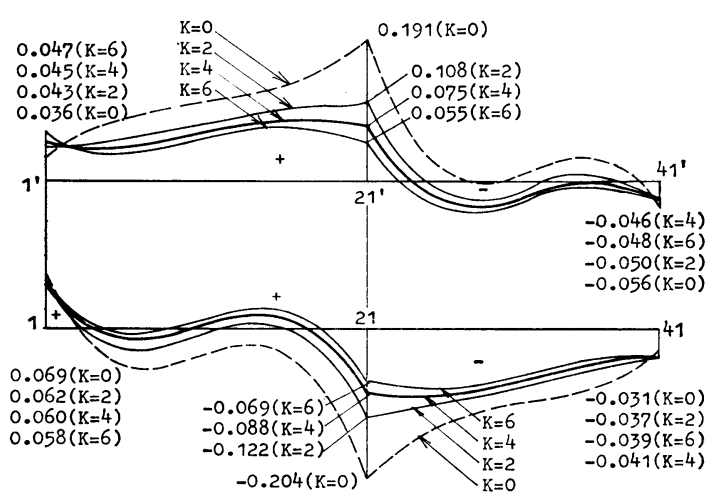

Fig. 8 Horizontal Cable Displacement, in Meters. 
trusses, and the twisting moment to act upon the suspended structure are shown in Figs. 8, 9, 10, and 11 , in which the values for the actual case of $K=4.0 \mathrm{~m}^{4}$ are plotted by thick lines and the results when the torsional rigidity of the suspended structure is disregarded, i.e., $K=0$, are shown by dotted lines.

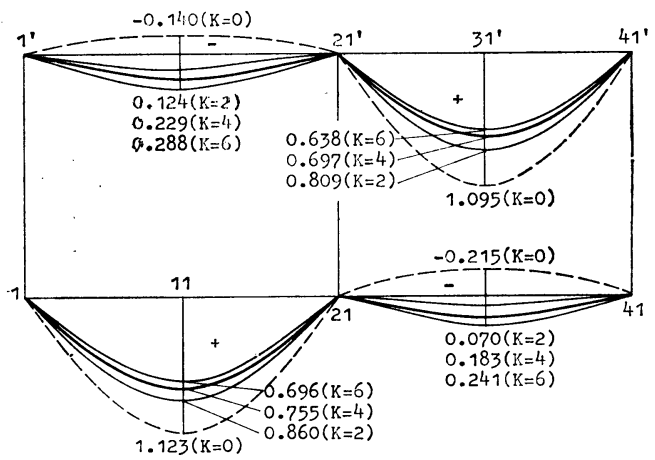

Fig. 9 Vertical Deflection of Cables and Stiffening Trusses, in Meters.

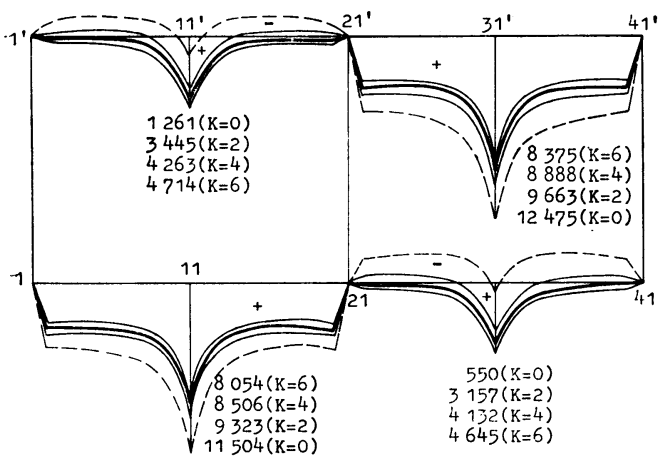

Fig. 10 Bending Moments of Stiffening Trusses, in Kilonewton-Meters.

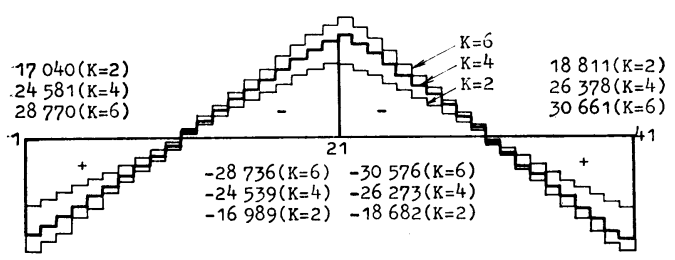

Fig. 11 Twisting Moment of Suspended Structure, in Kilonewton-Meters.

One major item of concern in the present example was the torsional deformation of the bridge structure, in particular, the torsion of the main tower and the twist of the roadway structure. The main tower top moves together with the cables resting thereon $0.088 \mathrm{~m}$ toward the $930-\mathrm{m}$ span on one side and $0.075 \mathrm{~m}$ toward the $850-\mathrm{m}$ span on the other side. This means that the tower top is twisted by $(0.088+0.075) / 27=0.006$ radians, a twist that may be considered practically insignificant.

The twist of the roadway structure is proportional to $y_{i}-y_{i}^{\prime}$, or $\bar{y}_{i}$, and becomes maximum at each span center as shown in Fig. 12. In the actual case of $K=4.0 \mathrm{~m}^{4}$, the maximum twist is about $2 \%$ which will hardly obstruct traffic on the bridge. Thus, it can be concluded that the torsional effect of the antisymmetric loading of Fig. 7 need not be feared insofar as viewed in the light of statics.

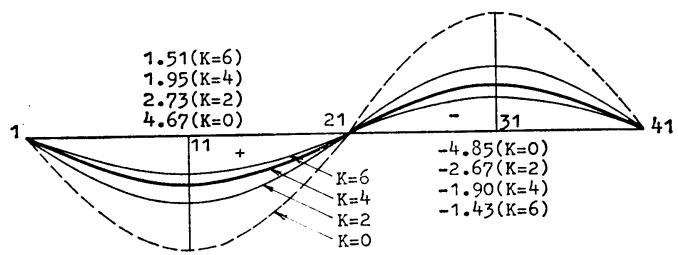

Fig. 12 Angle of Twist of Suspended Structure, in Radians $\times 10^{-2}$.

As regards the effect of the torsional resistance of the suspended structure, the results shown in Table 1 and Figs. 8 to 12 clearly show that the negligence of the torsional stiffness of the structure leads to quite erroneous results and that once the analysis is made by considering the torsional stiffness of the structure, there arises no great difference even if the equivalent torsion constant, $K$, varies from $2.0 \mathrm{~m}^{4}$ to $6.0 \mathrm{~m}^{4}$. Therefore, it can be said that enough exact results will be obtained by assuming an adequately evaluated, equivalent torsion constant.

\section{EXAMPLE II-THREE-SPAN RAIL/ HIGHWAY BRIDGE}

In Fig. 13 is shown a three-span bridge to carry a six-lane highway on the upper deck and two double-track railway lines on the lower deck, planned for the crossing of the Bisan Straits in Japan. Analyses were made on a tentative design of this bridge for the one-sided live loading shown in Fig. 14.

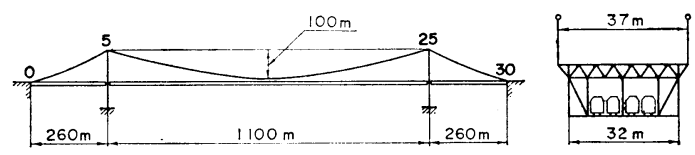

Fig. 13 A Tentative Design of Three-Span Rail/Highwry Bridge. 
The main span measures $1100 \mathrm{~m}$ between tower centers and both side spans $260 \mathrm{~m}$ from anchorage to tower center. The cables rest on movable saddles, sagging $100 \mathrm{~m}$ in the main span in the initial state. While the stiffening trusses are spaced $32 \mathrm{~m}$ apart, the cables are laid in a width of $37 \mathrm{~m}$ center to center. Therefore, $b_{c}=37 \mathrm{~m}$, $b=32 \mathrm{~m}$, and $b_{c} / b=1.156$. But, for comparison's sake, comparative computations were also made by assuming $b_{c}=b=32 \mathrm{~m}$.

The analysis was carried out, for approxima. tion's sake, by assuming equal span lengths for the cables and stiffening trusses. Each side span is divided into five equal panels of $52 \mathrm{~m}$ and the center span into twenty panels of $55 \mathrm{~m}$. Accordingly, the division points, i.e., panel points, were numbered $0,1,2, \cdots, 30$, as shown in Fig. 14, the towers being numbered 5 and 25 .

On either side of the bridge, the cable area is: $A_{c}=0.7705 \mathrm{~m}^{2}$; and the moment of inertia of the stiffening trusses: $I_{0,5}=I_{5,25}=I_{25,30}=10.31 \mathrm{~m}^{4}$. The equivalent torsion constant of the suspended structure was evaluated at $24.36 \mathrm{~m}^{4}$ in the side spans, and $20.73 \mathrm{~m}^{4}$ in the main span. The analysis is unrelated to the tower stiffness as the cables are free to move at tower tops.

The dead load to be borne by the cable on either side was estimated at $205.6 \mathrm{kN} / \mathrm{m}$ in the main span and $208.6 \mathrm{kN} / \mathrm{m}$ in the side spans. The horizontal cable tension due to these dead loads was computed as $H_{d}=311040 \mathrm{kN}$, from which $\kappa=$ 0.002058 .

Two loading cases shown in Fig. 14 were considered. In both cases, one-sided highway loading of $21.2 \mathrm{kN} / \mathrm{m}$ is applied on the main span. In Case 1 , railway loading of $39.5 \mathrm{kN} / \mathrm{m}$ per track is applied on two tracks spreading $370 \mathrm{~m}$ from tower 5 toward the main span center, and in
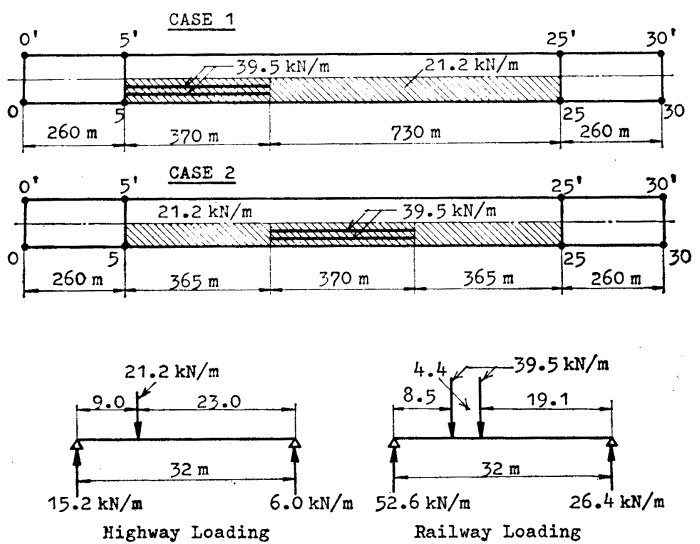

Fig. 14 Live Loading of Example II.
Case 2 on a $370-\mathrm{m}$ section in the middle part of the main span. The lines of action of the loads and the parts to be transferred to either side are shown in Fig. 14.

\section{(1) Results of Analysis}

In the present case, the horizontal cable tension is always uniform throughout one side of the bridge and its increments on the loaded and unloaded sides are denoted simply by $H$ and $H^{\prime}$, respectively. The computed values of $H$ and $H^{\prime}$ are listed in Table 2 as compared with the results. when $b_{c}$ is assumed to equal $b$. Table 2 shows. that there arises no great difference in the cable: stresses on the loaded and unloaded sides and the unequal spacing of the cables and stiffening:

Table 2 Increments in Horizontal Cable Tension, in Kilonewtons.

\begin{tabular}{l|ll|l}
\hline Item & \multicolumn{2}{|c|}{ Loading Case 1 } & \multicolumn{2}{|c}{ Loading Case 2 } \\
\hline$H$ & 34780 & $(34900)$ & $49830 \quad(50100)$ \\
$H^{\prime}$ & $22450 \quad(22250)$ & $33005 \quad(32740)$ \\
$H-H^{\prime}$ & $12230 \quad(12730)$ & $16825 \quad(17360)$ \\
\hline
\end{tabular}

N.B.: Values in parentheses are for $b_{c}=b$.

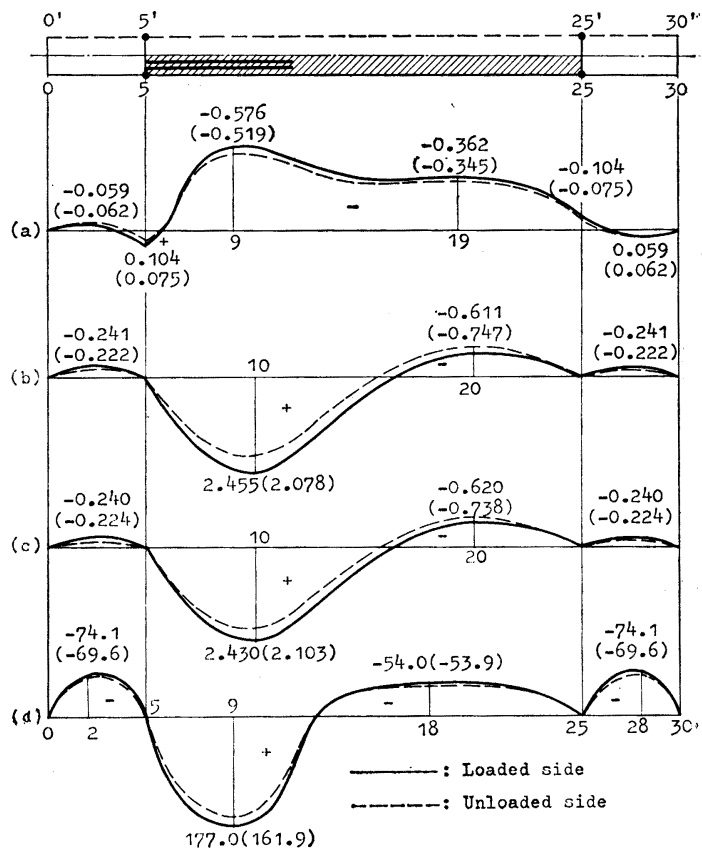

(a) Horizontal displacement of cables, in meters

(b) Vertical displacement of cables, in meters

(b) Vertical deflection of stiffening trusses, in meters

(d) Bending moments of stiffening trusses, in $\mathrm{WN} \cdot \mathrm{m}$

Fig. 15 Results of Analysis for Loading Case 1 (Dotted lines and parenthesized values refer to the unloaded side). 
Table 3 Values of Some Items as Compared with Those in the Case of $b_{c}=b$, Given in Parentheses.

\begin{tabular}{|c|c|c|}
\hline Item & Loading Case 1 & Loading Case 2 \\
\hline Horizontal cable displacement at tower top, in meters & $\begin{array}{ll}u_{5}=0.104 & (0.105) \\
u_{5}^{\prime}=0.075 & (0.075)\end{array}$ & $\begin{array}{ll}u_{5}=0.150 & (0.150) \\
u_{5}^{\prime}=0.110 & (0.109)\end{array}$ \\
\hline Maximum horizontal displacement of cable, in meters & $\begin{array}{ll}u_{9}=0.576 & (0.574) \\
u_{9}^{\prime}=0.519 & (0.522)\end{array}$ & $\begin{array}{ll}u_{7}=0.204 & (0.203) \\
u_{7}^{\prime}=0.185 & (0.186)\end{array}$ \\
\hline Maximum vertical displacement of cable, in meters & $\begin{array}{ll}v_{10}=2.455 & (2.451) \\
v_{10}^{\prime}=2.430 & (2.451)\end{array}$ & $\begin{array}{ll}v_{15}=2.428 & (2.428) \\
v_{15}^{\prime}=1.901 & (1.900)\end{array}$ \\
\hline Maximum deflection of stiffening truss, in meters & $\begin{array}{l}y_{10}=2.430 \\
y_{10}^{\prime}=2.103 \quad(2.451) \\
\end{array}$ & $\begin{array}{ll}y_{15}=2.392 & (2.428) \\
y_{15}^{\prime}=1.926 & (1.900)\end{array}$ \\
\hline Maximum bending moment of stiffening truss, in $\mathrm{MN} \cdot \mathrm{m}$ & $\begin{array}{ll}M_{9}=177.0 & (177.6) \\
M_{9}^{\prime}=161.9 & (161.4)\end{array}$ & $\begin{array}{ll}M_{15}=134.0 & (134.6) \\
M_{15}^{\prime}=120.8 & (120.1)\end{array}$ \\
\hline
\end{tabular}

Note: $u_{i}^{\prime}, v_{i}^{\prime}, y_{i}^{\prime}$, and $M_{i}^{\prime}$ refer to the unloaded side.

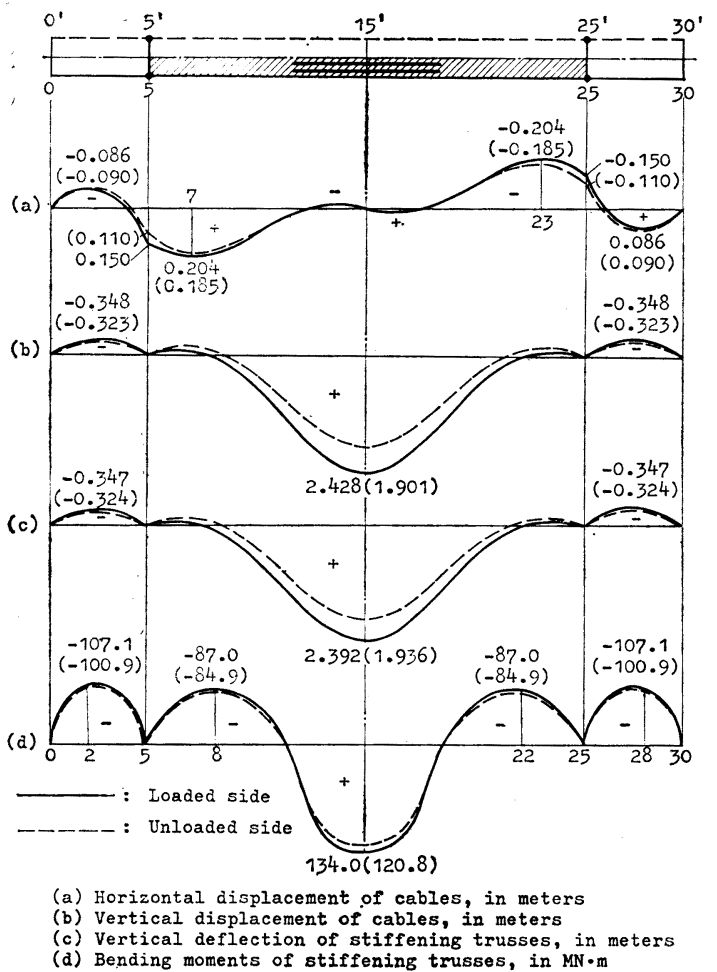

Fig. 16 Results of Analysis for Loading Case 2 (Dotted lines and parenthesized values refer to the unloaded side).

trusses exerts almost no influence upon the cable stress.

The vertical and horizontal displacements of the cables as well as the deflections and bending moments of the stiffening trusses are plotted in Figs. 15 and 16. The horizontal cable movement is not so insignificant as to be entirely disregarded, amounting to $0.58 \mathrm{~m}$ at point 9 in Case 1 . It must also be noted that at tower tops the cable on the loaded side move $0.10 \mathrm{~m}$ in Case 1 , and $0.15 \mathrm{~m}$ in Case 2 .

It goes without saying that the loaded side ${ }_{\wedge}^{\mathbf{Y}}$ is subjected to greater deformation and stress changes than the unloaded side. But, the difference is not so large as might be expected. In the stiffening-truss bending moments, in particular, the difference is quite insignificant as can be seen in Figs. 15 and 16.

To know the effect of the unequal lateral spacing of the cables and stiffening trusses, in Table 3 are compared the exact values of some characteristic items with the results obtained by assuming $b_{c}=b=32 \mathrm{~m}$. It can be seen that the unequal spacing of the cables and stiffening trusses exerts almost no influence on the structural behavior of the bridge.
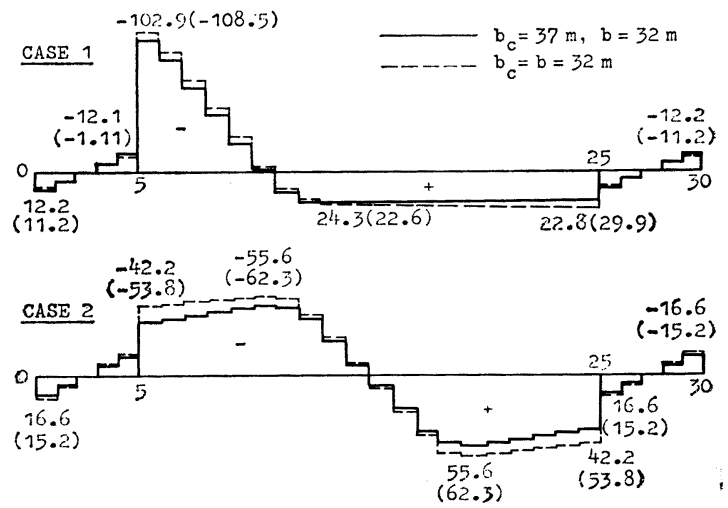

Fig. 17 Twisting Moment of Suspended Structure, in $\mathrm{MN} \cdot \mathrm{m}$ (Parenthesized: values for $b_{c}=b$ ). 
Table 4 End Reactions of Stiffening Trusses, in Kilonewtons.

\begin{tabular}{l|c|c|c|r}
\hline Loading & Point & $\begin{array}{l}\text { From } \\
\text { bending }\end{array}$ & $\begin{array}{c}\text { From } \\
\text { torsion }\end{array}$ & Resultant \\
\hline & 5 & 1840 & 3216 & 5056 \\
Case 1 & $5^{\prime}$ & 1576 & -3216 & -1640 \\
\cline { 2 - 5 } & 25 & -460 & 713 & 253 \\
& $25^{\prime}$ & -458 & -713 & -1171 \\
\hline \multirow{2}{*}{ Case 2 } & 5,25 & -960 & 1319 & 359 \\
& $5^{\prime}, 25^{\prime}$ & -922 & -1319 & -2214 \\
\hline
\end{tabular}

The twisting moment to act upon the suspended structure is shown in Fig. 17, in which the dotted lines show the comparative values when $b_{c}=b$. The maximum occurs at span ends in Case 1, and at quarter points in Case 2. The twisting moment must be balanced by antisymmetric end reactions of the stiffening trusses. As these torsional reactions are far greater than what will arise associated with the bending of the trusses, there occur negative resultant reactions as shown in Table 4. The end bearings of the trusses must be designed for these resultant reactions.

Twist of the roadway structure is a matter of concern related to the safety of railway operation. As shown in Fig. 18, the maximum angle of twist was found to be 0.0103 radians in Case 1 , and 0.0142 radians in Case 2. These correspond to changes in the cross grade of $1.0 \%$ and $1.4 \%$, respectively, and may be judged to cause no trouble.

It has be stated that the unequal spacing of the cables and stiffening trusses hardly affects the flexural behavior of the bridge. On the bridge's torsional behavior, however, it exerts certain influence as can be seen in Figs. 17 and
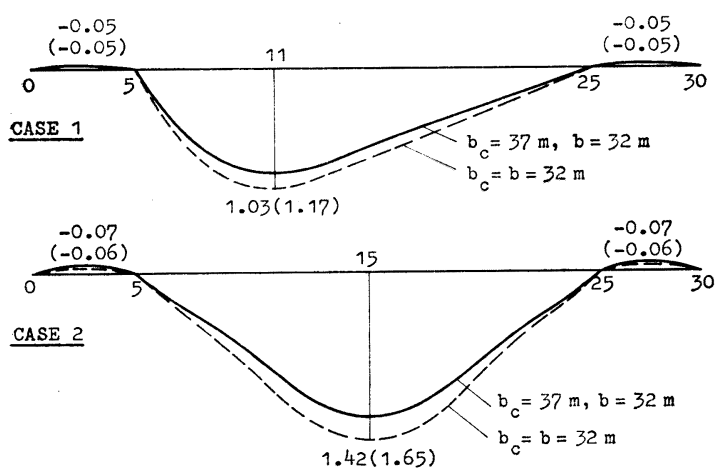

Fig. 18 Angle of Twist of Suspended Structure, in radians $\times 10^{-2}$ (Parenthesized: values for $b_{c}=b$ ).
18. To space the cables wider than the stiffening trusses is definitely effective in reducing the twist of the suspended structure. In particular, the angle of twist is reduced approximately in inverse proportion to the ratio of $b_{c}$ to $b$.

\section{CONCLUSION}

A method is presented for analyzing multispan suspension bridges subjected to asymmetrical loading that causes torsion in the bridge structure. Equations were derived by means of finite differences, viewing suspenders as isolated members which they are, with due consideration given to the deformation of cables.

Examples are presented for a four-span highway bridge and a three-span rail/highway bridge. By way of these examples it was found that asymmetrical loading conceivable under ordinary condition will present in general no serious problem insofar as statistically considered.

\section{APPENDIX. DERIVATION OF EQS. 41 AND 42}

From the theory of torsion, the twisting moment in the panel left of $i, Z_{i}$, is related to the angle of twist, $\phi_{i}$, by

$$
Z_{i}=G K_{m n} \frac{\phi_{i}-\phi_{i-1}}{\lambda_{m n}}
$$

When Eqs. 38 and 51 are noted,

$$
\phi_{i}-\phi_{i-1}=2 \frac{\Delta y_{i}}{b}=2 \rho_{m m} \bar{X}_{i} / b
$$

Substitution of Eq. 57 into Eq. 56 renders Eq. 41 .

The unbalance of the twisting moment across section $i, Z_{i+1}-Z_{i}$, must be balanced by a couple of reactions exerted by the stiffening trusses lying on both sides of the suspended structure. If these reactions are denoted by $Q_{i}$ and taken positive when they result in vertical loads to act on the stiffening trusses in the same direction as $\bar{P}_{i}$, the panel-point load, $L_{i}$, to be sustained by the trusses becomes

$$
\bar{L}_{i}=\bar{P}_{i}+Q_{i}-\left(b_{c} / b\right) \bar{T}_{i}
$$

The couple of $Q_{i}$, i.e., $Q_{i} b$, must equal $Z_{i+1}-$ $Z_{i}$. Therefore, if Eq. 41 is noted

$$
Q_{i}=\frac{Z_{i+1}-Z_{i}}{b}=\nu_{m n}\left(\bar{X}_{i+1}-\bar{X}_{i}\right)
$$

If $Q_{i}$ of Eq. 59 and $\bar{T}_{i}$ of Eq. 40 are substituted into Eq. 58, the result is

$$
\begin{aligned}
\bar{L}_{i}=\bar{P}_{i} & -\left[\left(b_{c} / b\right)^{2} k_{i}+\nu_{m n}\right] \bar{X}_{i} \\
& +\left[\left(b_{c} / b\right)^{2} k_{i+1}+\nu_{m n}\right] \bar{X}_{i+1} \\
& +\left(b_{c} / b\right)\left(b_{i}-b_{i+1}\right) \bar{H}_{m n} \ldots
\end{aligned}
$$

which is namely Eq. 42 . 


\section{REFERENCES}

1) Sih, Nan-sze: “Torsion Analysis for Suspension Bridges," Journal of the Structural Division, ASCE, Vol. 83, No. ST6, Proc. Paper 1431, Nov., 1957, pp. 1-8.

2) Baron, F. and Arioto, A. G.: "Torsional Analysis of Suspension Bridge Towers," Journal of the Structural Division, ASCE, Vol. 86, No. ST1, Proc. Paper 5196, Jan., 1960, pp. 143-169.

3) Baron, F. and Arioto, A. G.: "Torsional Behavior of Suspension Bridge Towers," Journal of the Structural Division, ASCE, Vol. 87, No. ST6, Proc. Paper 2879, Aug., 1961, pp. 1-30.

4) Irvine, H. M.: “Torsional Analysis of Boxgirder Suspension Bridges," Journal of the Structural Division, ASCE, Vol. 100, No. ST4, Proc. Paper 10464, April, 1974, pp. 789-812.

5) "Torsional Analysis of Suspension Bridges (in Japanese)," Special Report No. 6 of Task Committee on Steel Superstructures of Bridges between Honshu and Shikoku, JSCE, Aug., 1973.

6) Okamura, T. and Kataoka, T.: “Torsional Analysis of Suspension Bridges Considering Cross-Sectional Deformation of Stiffening Truss (in Japanese)," Proc. of JSCE, No. 231, No. 1974, pp. 31-43.

7) Fukuda, T.: "Analysis of Multispan Suspension Bridges," Journal of Structural Division, ASCE, Vol. 93, No. ST3, Proc. Paper 5261, June, 1967, pp. 63-86.

\section{NOTATION}

The following symbols are used in this paper:

$$
A_{c}=\text { cross-sectional area of cable; }
$$

$A_{i}, B_{i}, C_{i}=$ coefficients in basic equations;

$\bar{A}_{i}, \bar{B}_{i}, \bar{C}_{i}=$ coefficients in basic equations for antisymmetric loading;

$a_{i}, b_{i}, \bar{b}_{i}=$ parameters defined by Eqs. 9 and 43 ;

$b, b_{c}=$ spacing of stiffening trusses and of cables, respectively;

$D_{m n}, L_{m n}=$ constants defined in Eq. 27;

$d_{m}^{*}, \bar{d}_{m}=$ constants defined in Eq. 30 and in Eq. 50 , respectively;

$E, E_{c}=$ Young's modulus of stiffening truss and of cable, respectively;

$G=$ modulus of rigidity of suspended structure;

$H_{d}=$ horizontal cable tension due to dead loads;

$H_{i}, H_{m n}=$ increment in horizontal cable tension in panel left of $i$, and in span $m-n$, respectively;

$i, i^{\prime}=$ opposite lying panel points;

$I_{m n}=$ moment of inertia of stiffening truss in span $m-n$;

$K_{m n}=$ equivalent torsion constant of suspended structure in span $m-n$;

$k_{i}, \bar{k}_{i}=$ parameters defined in Eq. 20 and in Eq. 43, respectively;

$L_{i}=$ vertical load to be sustained by stiffening truss at $i$;

$l_{i}, \Delta l_{i}=$ initial length of cable segment left of $i$ and its increment;

$M_{i}=$ bending moment of stiffening truss at $i$;

$N_{d, i}, N_{i}=$ initial tension in cable segment left of $i$ and its increment;

$P_{i}, P_{i}^{\prime}=$ concentrated loads at $i$ and $i^{\prime}$, respectively;

$P_{i}^{*}=\left(P_{i}+P_{i}^{\prime}\right) / 2$, symmetric load;

$\bar{P}_{i}=\left(P_{i}-P_{i}^{\prime}\right) / 2$, antisymmetric load;

$Q_{i}=$ reactive force to counteract the unbalance of twisting moment;

$S_{i}=$ shear in panel left of $i$ of stiffening trusses;

$T_{i}=$ increment in suspender tension at $i$;

$u_{i}, v_{i}$, =horizontal and vertical displacement of cable;

$V_{d, i}, V_{i}=$ initial vertical component of cable tension and its increment in cable segment left of $i$;

$X_{i}=$ basic unknown defined in Eq. 14;

$y_{i}=$ vertical deflection of stiffening truss at $i$

$Z_{i}=$ twisting moment of suspended structure in panel left of $i$;

$\alpha_{i}, \beta_{i}, \gamma_{i}=$ parameters defined in Eq. 6;

$\eta_{m}^{*}, \bar{\eta}_{m}=$ reciprocals of $\mu_{m}^{*}$ and $\bar{\mu}_{m}$, respectively;

$\kappa=$ coefficient of horizontal cable tension;

$\lambda_{i}=$ panel length left of $i$;

$\lambda_{m n}=$ constant panel length in span $m-n$;

$\mu_{m}^{*}, \bar{\mu}_{m}=$ spring constant of tower $m$ for symmetric loading and for torsional loading, respectively;

$\nu_{m n}=$ constant defined in Eq. 41 ;

$\rho_{m n}=$ constant defined in Eq. 15;

$\phi_{i}, \Delta \phi_{i}=$ initial angle of cable slope and its increment after deformation; and

$\psi_{i}=$ angle of twist of suspended structure at $i$.

Note: Displacements and stress changes due to $P_{i}^{*}$ and due to $\bar{P}_{i}$ are identified as $H_{m n}^{*}$, $\bar{H}_{m n} ; T_{i}^{*}, \bar{T}_{i} ; X_{j}^{*}, \bar{X}_{i} ; y_{i}^{*}, \bar{y}_{i}$; et al. 